\title{
Analysis of the Geological Characteristics of Horizontal Well Fracturing Channeling in Honghe Oilfield
}

\author{
Jianming Guo ${ }^{1, a^{*}}$, Yan Dang ${ }^{1, a}$, Gang Wang ${ }^{1, ~ a}$ and Yanxia $\mathrm{Li}^{2, \mathrm{~b}}$ \\ ${ }^{1}$ School of Petroleum Engineering, Xi'an Shiyou University, Shaanxi xi' an 710065, China \\ ${ }^{2}$ School of Earth Sciences \& Engineering, Xi'an Shiyou University, Shaanxi xi' an 710065, China \\ ajmguo@xsyu.edu.cn, blyx4164@xsyu.edu.cn
}

Keywords: Horizontal well fracturing channeling; Fractured reservoir; Earth stress; Fault; Fractured zone; Micro-fracture

\begin{abstract}
In fractured reservoir, the inter-well formation of horizontal wells is likely to channel during hydraulic fracturing job, which results in higher moisture content and production drawdown sharply. Aim at the actual fracturing channeling condition of Honghe oilfield, the distribution characteristics of ground stress, fault and fracture zone of pressuring channel wells, and the naturally fractured formation and the influencing factors of them are analyzed, then making use of earthquake, outcrop, core, well logging, mud logging data, the fault ,fractured zone and the fracture distribution rule and scale in the research zone are quantitatively analyzed and described with the calculation; Finally, the effects of formation fault, fracture zone, nature fracture and ground stress on the pressuring channel is analyzed, verified and determined by using the oil well static and dynamic field data. Determination of the geological reasons can provide the project optimization basis for preventing horizontal wells fracturing channeling.
\end{abstract}

\section{Introduction}

The construction of Honghe oilfield is located in the south of the Ordos Basin Tianhuan syncline, exploration and development of layers includes Triassic chang8 and chang9 in Yanchang Formation, Jurassic Yan9 in Yan'an Formation and so on. In the process of horizontal wells development, horizontal wells fracturing channeling, formation damage and other problems happen frequently, showing initial high yield and rapid production decrease, rapid water cut increase, production instability, it has seriously affected the effect of increasing production \& injection and reservoir's overall development effect[1].

By the end of 2013, the number of Horizontal well fracturing in Honghe oilfield are 431, the average fracturing channeling rate is $24.13 \%$ [2]. Though strengthened controlling and monitoring wells adjacent wells in the fracturing process, adjusted fracturing job development mode, but after most of the wells are fractured channeling, oil production still decreased significantly. This paper focuses on geological characteristics and mechanism of fracturing channeling in Chang $8_{1}$.

\section{Analysis of Geological Factors of Fracturing Channeling Wells in Chang $\mathbf{8}_{1}$}

Fracturing channeling and geological factors are inseparable, it has been accepted that the horizontal section formation divided into three types, including fractured type, matrix type, fractured and matrix type, but in different or same fractured well segments, the formation is uneven. In order to optimize the reservoir, fracturing and production engineering programs, we must further study the qualitative and quantitative relationship between fracturing channeling and geological factors, including crustal stress, formation fault, fracture zone, fracture and so on. It can reveals the study area distribution characteristics and rules of geological factors, this is the basic guarantee to determine the geological mechanism and preventive measures of pressure channeling.

Analysis of Distribution of Stress Field, Fault \& Fracture Zone and Scale. Fault, fracture zone and micro-fracture are the passage of Fracturing channeling. The extending direction of natural and artificial fractures is decided by crustal stress, which creates fracturing channeling basic 
objective conditions, this is the internal reason of fracturing channeling, reservoir, fracturing and other projects is the external factors, in particular, the reservoir well network deployment develops the basic external conditions of fracturing channeling[3]. Most of the horizontal section of the study area spread northwest-southeast direction, deploy $345^{\circ}-165^{\circ}$, so, by overlap processing all the wells in the study area with the stress field, fault fracture zone and fracture distribution, it can be seen that the majority of wells exist complete or local penetration fault, fracture zone, fracture, and fracturing channeling or not is directly related to the distribution range and scale of them. Artificial fractures direction develops in $60^{\circ}-75^{\circ}, 85^{\circ}-90^{\circ}, 105^{\circ}-120^{\circ}$ due to crustal stress, which fracture extension process meets Fault, fracture zone and fracture, it will greatly improve the orthogonal, or nearly horizontal wells channeling orthogonal channel, if it encounters formation water, increase in rate of water content is inevitable with other fracturing channeling damage also appeared.

Naturally Fracture Formation and Their Influencing Factors. Through data research, especially preexisting research results related to the study area, the study summarizes influencing factors of natural fractures.

From three-dimensional seismic profiles provided by North China Branch, and combined with surrounding outcrops and core observation, the fault in this study area has the following characteristics: The fault is mainly high angle faults or vertical fractures; fracture dip is generally greater than $75^{\circ}$. The main faults direction is north west, north-east. Fracture density is related to fault, it controls fracture development degree, and the control region is 150 meters [3].

The main fracture zone is controlled by the fault. The position which the structural curvature changes obviously is the best part of fractures development, followed by broken nose, folds and axially block the intersection area. The position of fault intersections are often the most developed areas of fractures. The correlation between natural fracture and sedimentary facies, the thickness of sand body, rock property is not obvious.

Naturally Fracture Identification. Whether faults, fracture zone, fractures exist or not can be identified from different sides by outcrops, seismic, well testing, well logging, production data and so on. But different approach has its relevance, applicability and limitation, a comprehensive analysis and treatment is needed.

At first, Fracture was identified by logging. Fracture identification from imaging logging has a high vertical resolution and coverage hole, plate structure is designed in eight inches borehole, its vertical resolution and borehole coverage is 0.2 inches and $80 \%$. It can be clear and intuitive to reflect the macro geological phenomena. For example, fractures, suture line, muddy strip, corrosion holes, bedding, and other tight formations, imaging logging geological phenomenon is mainly characterized by the image feature. Since imaging contained rich messages are reflected mainly from the shape of the color and color change, therefore, we usually classify the imaging mode by imaging of color and form [4].

Using imaging logging and core data in fracture development segment describe curve feature and scale recognition mark in conventional logging. By a large number of field-related data showed that the sine curve in the study area imaging logging is basically characterized by high-angle fractures, and the corresponding cores also develops high-angle fractures. On the resistivity curve, the curve of the amplitude difference is obvious in corresponding segment of fracture development. At the same time, other curves having the following characteristics [5][6][7]:

1) Caliper curve (CAL) appears expanding phenomenon;

2) Gamma ray (GR) curves abnormally high;

3) Deep and shallow resistivity curve (R) sharp appears ups and downs;

4) Acoustic wave (AC) and neutrons (CNL) curve increased slightly, density curve (DEN) decrease.

In fracture development segment display by imaging logging, the corresponding conventional curves also have the above characteristics.

Usually the more sensitive logging series for micro-fractures include: deep and shallow investigation laterolog, microspheres focused Logging, deep induction resistivity logging, acoustic 
logging, neutron logging, density and caliper logging, but the opening degree of micro-fractures and filling substances have a great effect on the logging parameters.

Second, The reaction of comprehensive logging parameters are relatively obvious to naturally fracture, it display for the groove surface and the gas measurement value directly, when the microfractures pressure is higher, it is often accompanied with rising gas logging parameters, appearing oil bloom in the groove surface, rising bubbles and other features[8].

Due to the low pressure and drilling fluid column pressure imbalance, it will lead the development section of part micro-fractures to happen dropout, return loss and other phenomena.

In the fractured well section with oil, groove surface display microscopic parameters including liquid level increased height, crude oil, oil slick, bubbles, accounting groove surface area ratio etc.

Gas measurement total hydrocarbon microscopic parameters include gas measurement total hydrocarbon value-added and aftereffect length.

Statistics with 10 groove surface showing wells (all overflow occurred), the oil slick and needlelike bubbles are seen on groove surface, oil slick, bubble accounts for $3 \%$ to $80 \%$ of the whole groove face, gas measurement value of groove surface showing section is between $9.7 \%-99.6 \%$.

Qualitative and Quantitative Description of the Naturally Fracture. Fracture parameters include fracture opening, porosity and permeability. Logging data were used to calculate fracture parameters on the basis of predecessors' research, including calculating for fracture opening, fracture porosity, permeability and so on.

Luo Zhenyao [6] deduced the calculation formula of fracture opening degree of different dip angles according to the relationship between fracture and borehole on the basis of A. M. Sibbit and Q. Faivre et al study [7]. The calculation formulas of fracture porosity and permeability are derived by A.M. Sibbit and Q. Faivre respectively according to different reservoirs. In this paper, we use the cube model formula proposed by Zhao Liang Xiao [8] [9].

According to the above formula, we estimate the fracture parameters in the study area of the Vertical section, single well calculation results as shown in Fig. 1.

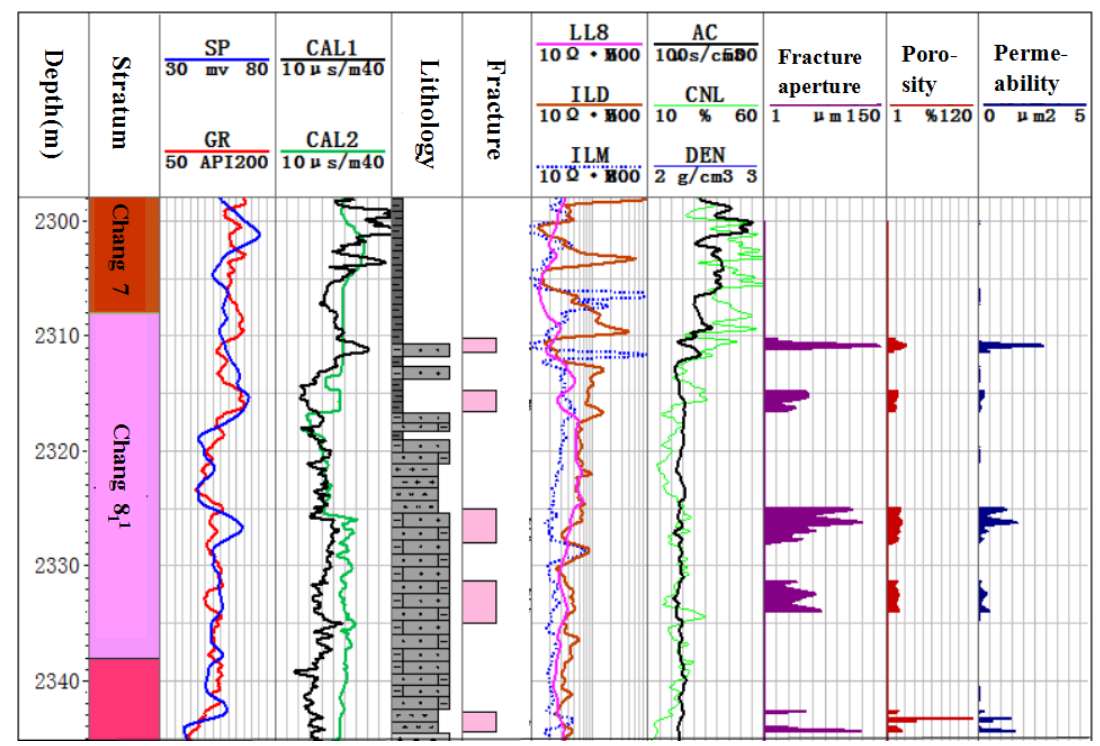

Figure 1. Comprehensive map of fracture identification in a well

Weighting Factor Calculation of Naturally Fracture Development. In the process of horizontal well testing, it needs to multi stage fracturing and combine production for the whole well, single reservoir can't be compared with test results in the study area. In order to adapt to compare with the test results, some parameters must be considered, such as horizontal section fluorescence logging display levels and length, gas logging components interpretation results and length, quantitative fluorescence interpretation results and length, the logging interpretation of porosity, permeability, deep lateral induction resistivity and acoustic time high-low and duration, logging interpretation fracture development duration and logging groove face showed weighting coefficient, 
cumulative duration after gas logging etc, we research the contribution of these parameters in the single well production capacity and takes each parameter weight value finally.

Weighting factor calculation method for the fracture development: $M=\{$ logging grooved surface gas peak value(\%), logging interpretation fracture length(m), logging groove surface display duration(h), horizontal section length(m)\}.

Fractal Dimension Calculation of Naturally Fracture Distribution. Main method for the determination of fractal dimension of fracture system is grid-coverage method. It is a main method to use graphics to determine the fracture fractal dimension, the main application dates are the core, imaging logging data, outcrop and seismic data [10]. Using this method to calculate, the fractal dimension of distribution of natural fracture is 1.2 in chang8 reservoir. Under this dimension, the presence of natural fractures has inevitably a certain influence on artificial fracture.

From the above, according to the tectonic activity in the study area, 3D seismic interpretation data etc, we can determine the earth stress, the distribution of fault and fracture zone, based on this, according to the fracturing channeling distribution position and thickness of sand body, sedimentary microfacies and logging data, we can obtain classification and distribution prediction of fractures in the study area.

\section{Quantitative Analysis of Geological Characteristics and Fracturing Channeling Mechanism}

3D seismic, well-testing(conventional and special), well-logging, lithology, outcrop, logging visual display for the groove surface and gas measurements, the qualitative and quantitative identification for characteristics of fracturing curve production data, evaluation fracturing channeling geological characteristics and law; requiring to further divide quantitatively geologic factors of fracturing channeling between the horizontal section of horizontal well in study area, combined with the actual data and theory, macro and micro analysis, throughout all kinds of materials, methods, learn from each other information fusion processing. The main control geological factors and mechanism analysis of fracturing channeling is as described below.

Position Relationship Analysis of Well Groups. There are 71 horizontal wells in the study area adjacent wells of fracturing channeling is up to 104, according to the location relations of the well groups can be divided into three types of all-inclusive, half inclusive and dislocation. Fracturing channeling rate were $62.5 \%, 21 \%$ and $0 \%$. The 42 group dislocation horizontal well didn't have fracturing channeling when spacing between $68-844 \mathrm{~m}$, it shows that the maximum horizontal principal stress in the study area has absolute control of fracturing fracture prolong directions. When well groups dislocation, adjacent wells can effectively avoid the artificial fracture, adjacent wells avoid to be fractured channeling; Remove dislocation well groups, the number of well groups decrease from 104 to 62 .

Analysis of Geological Main Control Factors. Under the condition of natural fracture extension direction and horizontal well section orthogonal, the geological characteristics inter-well is the defining factor. it is the easiest for complete penetration fault to lead fracturing channeling in the process of fracturing. Easier for local penetration fault and fracture development, fracture zone, few for micro-fracture, It is difficult for matrix. Other a key factor is the concentration degree of the defining geological factor.

\section{Conclusion}

There is no doubt that the influence of the study area fault and fracture development will come into being fracturing channeling frequently in horizontal well, Research shows that: Main geology control factors of fracturing channeling are fault, fracture zone, natural fracture and mutual superposition; Orientation of the structure principal stress (about $75^{\circ}$ ) is primarily represented by the NEE, so objective conditions of fracturing channeling are formed.

Fractures are controlled by faults, tectonic, sedimentary face, sand body thickness, lithology, they have no directly impact fracturing channeling, but they affect the development degree of the fracture. Inter-well geological characteristics types can be divided into fault (complete, local), 
natural fracture (fracture full development, development, part development, no development-matrix and their mixture), it is very uneven distribution.

According to statistics of inter-well geological characteristics, showing that more fracturing channeling wells are in through fault or local fracture zone connection area, less fracturing channeling wells are in the whole fracture zone, through fault and whole fracture zone area.

\section{Acknowledgments}

In this paper, this research was sponsored by the Natural Science Foundation of Shaanxi Province (Project No. 2013JM5006) and North China Company, SINOPEC, Study on the Comprehensive Control Technology of Horizontal Well Fracturing Channeling in Honghe oilfield (Project No. 34550000-13-ZC0609-0010).

\section{References}

[1] H Zhang: Journal of North China Geology and Mineral Resources, Vol. 13 (1996) No.1, p.87 (In Chinese).

[2] J. Zhang: The fracture development characteristics and its relationship with the development of the chang8 in ZhemJing area, (MS., Chengdu University of Technology, China 2010), p.28 (In Chinese).

[3] W. C. Tan: Study on prediction method of fracture in low permeability reservoir, (MS., Changjiang University, China 2011), p.30 (In Chinese).

[4] S. M. Zhang, X. Q. Ding and C. Yi: Well Logging Technology, Vol.35 (2011) No.1, p.36 (In Chinese).

[5] F. M. Zhang, Y. G. Chen, C. R. Shao and S. C. Li: Well Logging Technology, Vol.34 (2010) No.4, p.339 (In Chinese).

[6] Z. Y. Luo: Geophysical Log, Vol.14 (1990) No.2, p.83 (In Chinese).

[7] Sibbit A.M and Faivre O: The Twenty-Sixth Annual Meeting of the Association of Well Log Analysis (Petroleum Industry Press, China Beijing, 1989, p.96).

[8] Kajari Ghosh, Shankar Mitra: AAPG Bulletin, Vol.93 (2009) No.8, p.955.

[9] Stephen E Laubach, Jon E Olson and Michael R: AAPG Bulletin, Vol.93 (2009) No.11, p.1413.

[10] W. Li: 2009 Study on reservoir characteristics and fracture mechanism based on Fractal Theory (Ph.D., Daqing Petroleum Institute, and China 2009), p.50 (In Chinese). 